\title{
SIMULTANEOUSLY OBSERVATIONAL STUDY OF FILTERGRAMS, VELOCITY AND VECTOR MAGNETIC FIELDS FOR A SOLAR FLARE ON 7 Oct. 1987
}

\author{
LIN Yuanzhang, ZHANG Hongui, IIAN Feng and I.IU kening \\ Beijing Astronomical Observatory, Clinesc Acudemy of Sciences \\ Beijing 1000s0, Clina
}

\begin{abstract}
In this paper are described the simultancously observational results of filtergrams, Dopplergrams and vector magnetograms for á solar flare in the active region NOAA/USAF . $180^{\circ} 2$ on 7 Oct. 1987 with the solar telescope-magnetograph of Beijing Astronomical Observatory. From the analyses of these data, some conclusions were obtained.
\end{abstract}

1. Observational Data In 0050-0110 UT on 7 Oct. 1087 a small solar flar, with its maximum at 0055 UT and an apparent area of $27 \times 10^{-6}$ solar disk, occured in the active region NOAA/USAF $+862(\mathrm{~N} 33$, E16) (Solar-Gcophysical Data,1987). The high-quality chromospheric filtergrams and Dopplergrans (in $\mathrm{H}_{\beta}$ ) as well as the photospheric filtergrams, longitudinal and transverse magnetograms (in $\mathrm{Fe}$ I 5321) were obtained simultancously with the solar telescope-magnetograph of Beijing Astronomical Observatory around the flare period (Table 1).

Tabel 1. Observations around flare period

\begin{tabular}{|c|c|c|}
\hline UT & Observation & Wave lemgth \\
\hline 0031 & Photospheric filtergram & IC I 5324 \\
\hline 0035 & $\begin{array}{l}\text { Photospheric longitudinal } \\
\text { tnagnetogram }\left(B_{\|}\right)\end{array}$ & Fe 15324 \\
\hline 0055 & Cliromospheric filtergram & $\mathrm{H}_{\beta}$ \\
\hline 0058 & Cliromosplieric loopplergram & $\mathrm{II}_{\beta}$ \\
\hline 0114 & $\begin{array}{l}\text { Plootospheric longitudinal } \\
\text { magnetogram }\left(\mathrm{B}_{\|}\right)\end{array}$ & Fe I 5324 \\
\hline 0121 & $\begin{array}{l}\text { Pliotosphlicric transverse } \\
\text { magnelogram }\left(13_{l}\right)\end{array}$ & Fe I 532.1 \\
\hline
\end{tabular}

The $35 \mathrm{~cm}$ telescope is ecpupped with a tumalole birefrigent filter of $0.12 \mathrm{~A}\left(\mathrm{II}_{p}\right)$ and $0.15 \mathrm{~A}(\mathrm{Fe}$ I 5324) bandwidtlis. (The Cooperative Development Geoup, 1085; $\mathrm{Ai}$ and IIu, 1986). A $4 \mathrm{~cm}$ solar inage is formed on the focul plane where is installed a detector of CCD with $500 \times 582$ pixels, which correspo ids to at view field of $4^{\prime} \times 5.3$. Thus the spatial resolution of the solar image on the display screen is $0 . " 5$. Because each measurement on the magnetograms was taken from the average of measurements in $3 \times 3$ pixels, the spatial resolution of magnetograms became 1."5. The temperal resolution of filtergrams is $1 / 12.5$ second, while that of the Dopplergrams and magnetograms are 40 seconds (255 superposition). The sensibilities of measurements for $B_{\|}$and $B_{\perp}$ are 20-30 gauss and 150 gauss tespectively, whereas that of Donplergrams is $40 \mathrm{~m} / \mathrm{sec}$.

In Fig. 1 are shown the filtergrams in $\mathrm{Fe} \mathrm{I} 5324$ and $\mathrm{H}_{\beta} . \mathrm{H}_{\beta}$. Dopplergrams and $\mathrm{B}_{\|}$magnetograms for the NOAA/USAF 4862 arount the flate period. Also in Fig.2 and Fig.3 are shown the $B_{\|}$and vector magnetograms with contours.

2. Analyses and Conclusions Since hat the $\mathrm{H}_{\beta}$ emission of solar flares is far weaker than $\mathrm{H}_{\alpha}$ emission and it mainly concentrate in ar kernels, so that the morphology of the flare in Fig. 1b is probably more similar to the $\mathrm{I}_{\alpha}$ flare icruels. Usually these kernels are most likely developed from the original briglit points in flares (Lin and Gaizaushias, 1987).

-From thle comparisions of Fig. 1b with 1c, Fig.2 and Fig.3, one can see that this flare consists of five kernels and only kernel $B$ is located near the magnetic neutral line, others are situated enuch far from that ( $A$ in positive polarity; $C, D$ and $E$ in negtive polarity). However all keruels are located in those regions where the trimsverse field $\mathrm{D}_{\perp}$ are quite strong, implying that they are likely located 

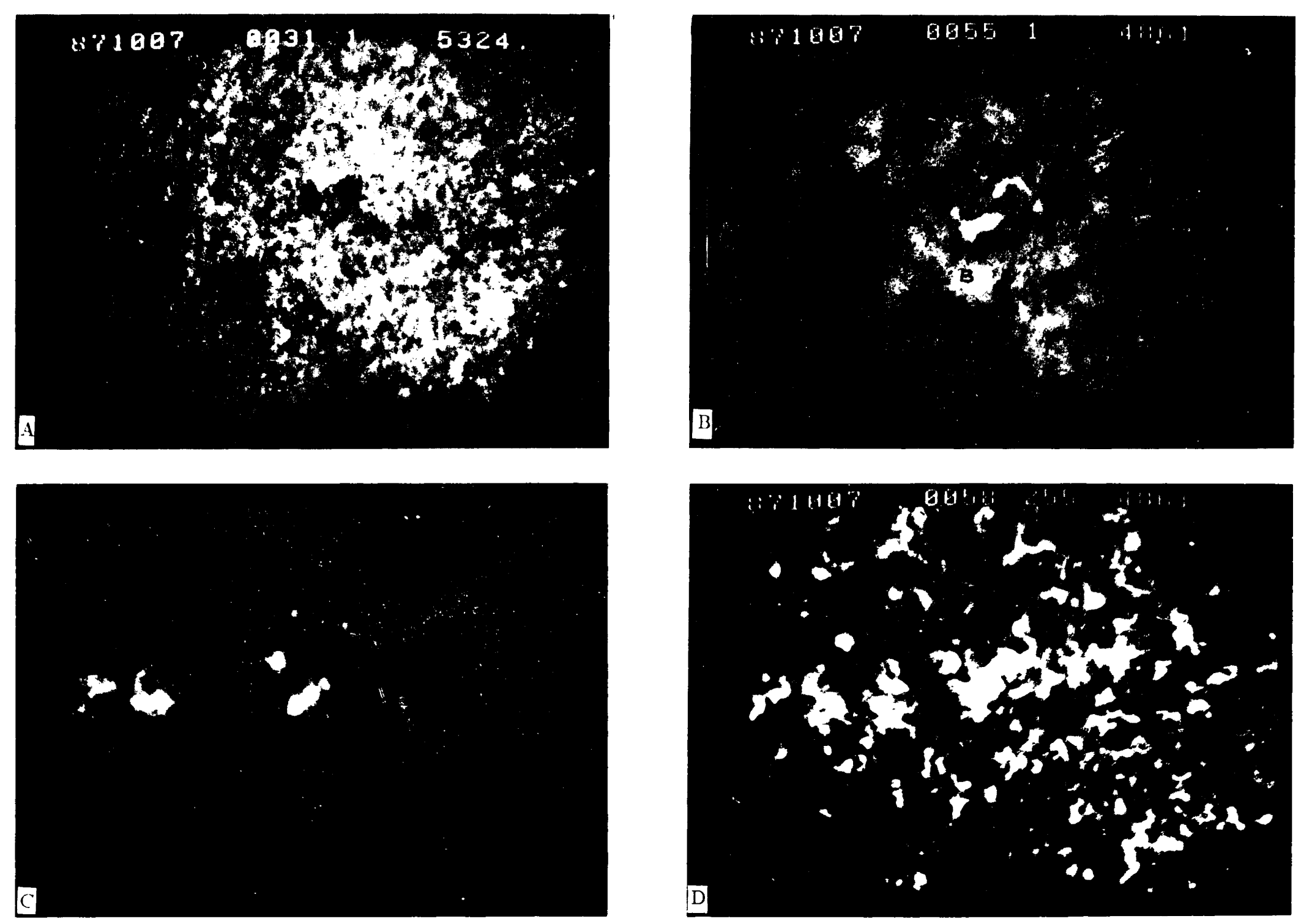

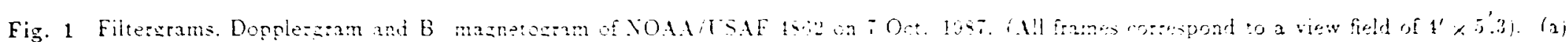

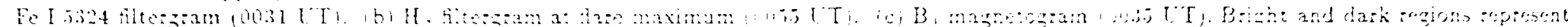

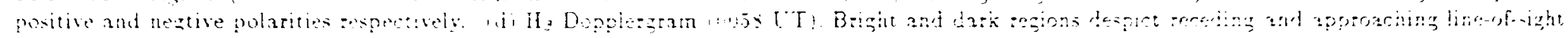




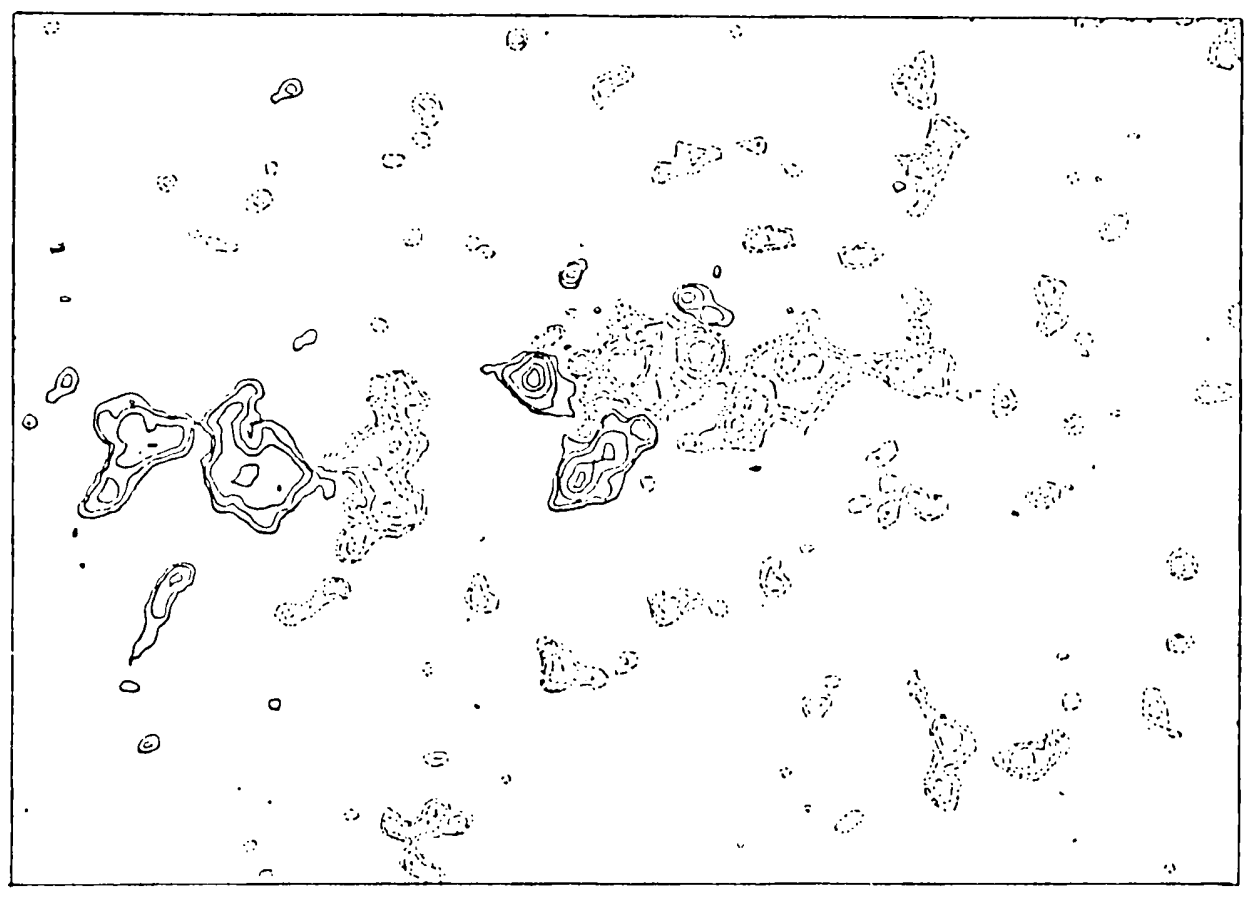

Fig 2 'The $\mathrm{B}_{\|}$magnetogram with contours for NOAA/USAF' 1862 on 7 Oct. 1987 (0035 U'T). Solid and dutted contours inclicate positive and negtive polarities respectively. The contour levels are $\pm 20, \pm 10$, $\pm 80, \pm 160, \pm 320, \pm 6.10, \pm 1280, \pm 1600$ gauss. The area shown is $270 \times 190$ are sec ${ }^{2}$.

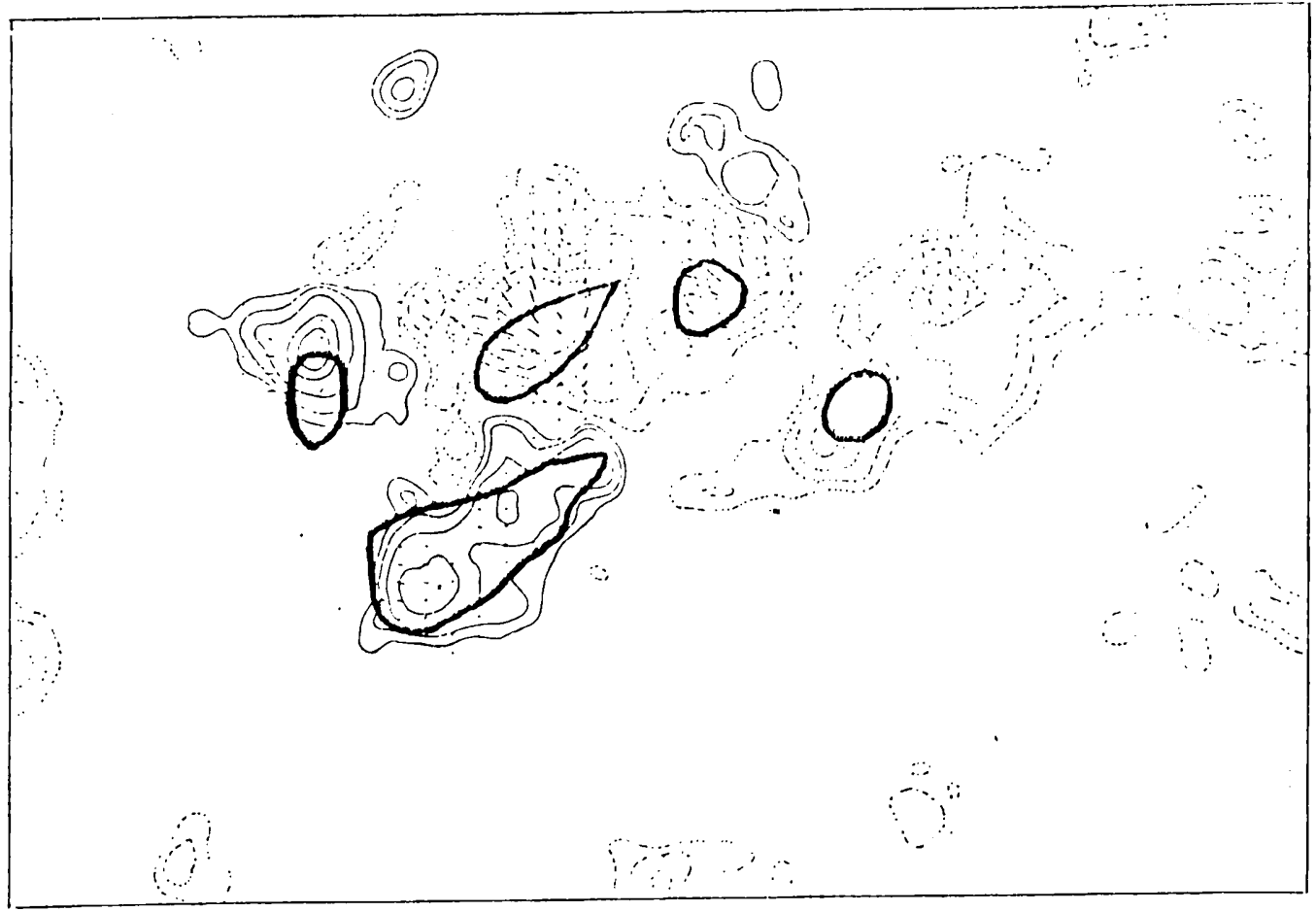

Fig. 3 The $B_{\|}$and $B_{\perp}$ magnctogram witl contours and linc sepuents for NOAM/USAF 1862 on 7 Oct.

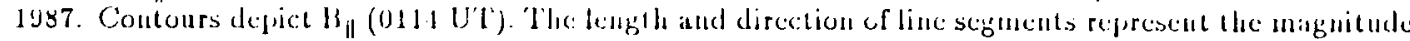

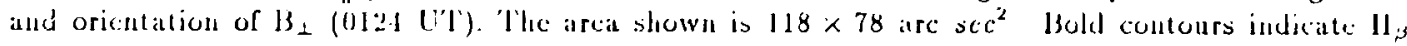
emission. 
in the regions with atrong shear and hence naxinnm logitudinal electric current densities. These results are consistent with those in Lin and Gaizaushis (1987), Hagyard el al. (1984), and Ilagyard et al. (1985). The conparision of Fig. 1b with Fig. 1d indicates that all the positions of five kernels correspond to the bright regions in Fig. 1d, showing that the kernels possess line-of-sight velocities down to the solar surfice. Further study are needed to determine whether this result support the theories which consider optical flates are cansed by the accelerated particales from coroud down to chromospliere.

Finally, comparision of two $\mathrm{B}_{\|}$magnetogräns at $0035 \mathrm{UT}$ (preflare) and $011.4 \mathrm{UT}$ (postflare) shows that no remarkible defference conld be fombl between them, and therefore it demonstrates onece more that wo sulsstantial change occured in longitudinal magnetic fields between onset and cond of the flare.

\section{REFERENCES}

[1 ] Ai Ranoxiang and Jlu Yúfen: 1936, Acta Astronomica Sinica, 27, 173.

[2 ] II agyard, M.J., Smith, J.IS., Jr., 'leulser, D. and West, E.,.: 198.4, Solar P'hys. 91, 115.

[3 ] Jaggyard, M.J., Went, E.A. and Suthith, J.13., Jr.: 1985, in C. de Jager and Chen Biato (cds.), "Proccedings of Kinuming Workshop on Solar Physics and Interplanetary Travelling Phenomena." Vol. I, Science P'ress, Bcijing, Clina, p.179.

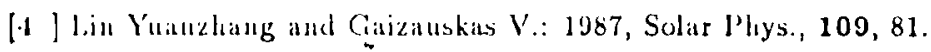

[5] Solar- Cicoplyysical Dat a: 1987, No.519, I'art 1, p.1.1.

[i ] 'I lic Cooperative Development Gronp, Acidemia Sinica: 1985, in C. de Jager and Chen Biao (eds.), "Proccedings of kinuming Workshop, on Solar Pliysics and Interplanetary 'Iravelling P'henomena." Vol.2, Science Press, 13cijing, Clinia, p.1204. 